\title{
The influence of an ECAP-based deformation process on the microstructure and properties of electrolytic tough pitch copper
}

\author{
Marta Lipińska $^{1, *} \mathbb{D}$, Lech Olejnik ${ }^{2}$, and Małgorzata Lewandowska ${ }^{1}$ \\ ${ }^{1}$ Faculty of Materials Science and Engineering, Warsaw University of Technology, Wołoska 141, 02-507 Warsaw, Poland \\ ${ }^{2}$ Institute of Manufacturing Processes, Warsaw University of Technology, Narbutta 85, 02-524 Warsaw, Poland
}

Received: 31 August 2017

Accepted: 10 November 2017

Published online:

20 November 2017

(C) The Author(s) 2017. This article is an open access publication

\begin{abstract}
Samples of electrolytic tough pitch copper were deformed in equal channel angular pressing with enhanced productivity to quickly refine its initial coarsegrained microstructure at room temperature. The evolution in microstructure and changes in a broad range of properties were compared to a sample in the undeformed state. The microstructure evolution was evaluated using electron backscatter diffraction for both states and transmission electron microscopy for a detailed microstructure characterization of the deformed sample. The microstructure observations were correlated with the results of tensile tests, electrochemical tests in $3.5 \mathrm{wt} \% \mathrm{NaCl}$, electrical conductivity measurements and thermal stability up to $200{ }^{\circ} \mathrm{C}$. The ECAP process employed in this study caused a grain refinement from about $16 \mu \mathrm{m}$ to about $600 \mathrm{~nm}$. The microstructure refinement caused a 50\% increase in both the YS and UTS. The elongation to failure, due to the high amount of LAGBs, maintained a high value of $13.3 \%$. The corrosion and pitting potentials were higher for the deformed sample. Furthermore, the grain refinement caused a decrease in electrical conductivity from $100.2 \%$ IACS to $93.1 \%$ IACS, a drop of $7 \%$ IACS. The deformed sample displayed thermal stability up to a temperature of $175{ }^{\circ} \mathrm{C}$, where there was a drop in micro-hardness of more than $10 \%$.
\end{abstract}

\section{Introduction}

Due to its high electrical conductivity, electrolytic tough pitch (ETP) copper is mainly used in industry for constructing electrical equipment and for electrical installations. For such applications, in addition to low resistance, the best possible mechanical strength and high corrosion resistance are required. Pure metals often show inadequate mechanical properties, and so, most are hardened by cold metal forming. Strain hardening, however, is known to slightly worsen a metal's electrical properties [1-4]. In the case of demanding applications, copper alloys are used. The addition of alloying elements significantly

Address correspondence to E-mail: marta.lipinska@inmat.pw.edu.pl 
improves strength, but decreases electrical conductivity $[5,6]$. A possible solution of this complicated problem is to refine the microstructure of the pure metal. Grain refinement results in an extremely significant increase in mechanical properties [7]. There is hope that this can help balance these counteracting features.

Grain refinement can be accomplished by severe plastic deformation (SPD) [8] methods. If the average grain size is reduced to below $1 \mu \mathrm{m}$, the microstructure is defined as ultrafine-grained (UFG). One of the most popular SPD methods is equal channel angular pressing (ECAP) [9-11]. In this method, a sample is pressed through two intersecting channels having the same cross-sectional dimensions, and the deformation is conducted by the intensive simple shear at the intersection of the channels. In its classical form, ECAP is known as too cumbersome to be used in industry for manufacturing UFG metals. One of its main limitations is that the sample must be removed from the die and reinserted after each pass [9]. In order to achieve significant grain refinement by implementing high strain, this operation must be repeated several times, which is both labor- and timeconsuming, and limits ECAP's potential for industrial applications. As a possible solution, equipment with an enhanced number of angular channels has been considered, which makes it possible to reduce the number of passes required to obtain the same material properties. In the present study, a modified multi-turn ECAP (mtECAP) for increased productivity was employed. Such a configuration, having as many as 5 turns, was experimentally investigated in [12]. The design of a 5-turn ECAP die for a combined route $\mathrm{C}+\mathrm{BC}$ has also been patented [13]. A 3-turn ECAP channel was successfully proved to produce UFG aluminum with route Bc [14], which is known as the most effective processing route for grain refinement [15]. A simplification enabling ECAP with route $C$ in 2-turn (S-shaped) angular channel was used by Raab [16] in a laboratory rig to obtain UFG copper at room temperature and UFG titanium at elevated temperature for research purposes. An industry standard tooling for mtECAP with an S-shaped channel was introduced in [17], and recently, in [18], mtECAP technology for enhanced productivity was thoroughly described. Using an S-shaped channel, shearing in two deformation zones takes place during a single processing pass, which considerably increases the efficiency of the process and reduces the number of passes required to achieve a refined microstructure. The grain refinement achieved in multi-turn and conventional ECAP with the same number of shearing zones is the same. Therefore, by applying a larger number of shearing zones in one pass, effectiveness is increased by the same number of times. Also, the properties of such materials, such as micro-hardness, are the same [12]. Any mtECAP can decrease the number of passes compared to conventional the ECAP process in order to obtain the same grain refinement in the same material. Other advantages of using a multi-turn channel rather than conventional ECAP include a higher proportion of ultrafine grains, more uniform strain distribution and a relatively isotropic microstructure and mechanical properties [19]. Moreover, even in tail pieces a uniform strain distribution is observed when using this method [16]. Furthermore, in contrast to the conventional ECAP process, the shape of the sample remains unchanged after the deformation process. The mtECAP die having an S-shaped channel for the present study was developed based on the methodology described in [20].

The increased number of grain boundaries, which inhibit the movement of dislocations [7], causes hardening. This phenomenon has been widely described for pure copper processed using various SPD methods, such us high pressure torsion (HPT) [21-23], accumulative roll bonding (ARB) [24] or different types of ECAP [25-28]. However, grain refinement also affects functional properties such as corrosion resistance and electrical conductivity. As is widely known, the smaller the grains, the greater the total surface area of the grain boundaries which, as areas of increased energy, can stimulate corrosion processes or change corrosion behavior in relation to their coarse-grained counterparts [29, 30]. The greater number of grain boundaries can also affect the material's electrical properties. However, the electron scattering caused by the grain boundaries and dislocations is less than that caused by other structural defects [31]. This work was initiated to thoroughly investigate the correlation between the microstructural factors (grain shape and size as well as grain boundaries misorientation), the mechanical and functional properties (electrical conductivity and corrosion resistance) and the thermal stability of the deformed sample. This is the first time to our knowledge that such a combination of properties has been investigated for pure copper in the undeformed 
and unconventionally deformed states. The present work may serve to broaden the possible uses of ECAP-based methods in industry by presenting the properties that are possible to obtain in ETP copper deformed by this process.

\section{Materials and methods}

The material examined here was an electrolytic tough pitch copper with the chemical composition presented in Table 1, where the main impurities are shown. The purity of the material was at least $99.9 \mathrm{wt}$ $\%$, which is the fundamental requirement for most electrical applications.

The material was received in the form of a round bar with a diameter of $35 \mathrm{~mm}$ extruded to achieve a half-hard state (H14). Samples with a cross section of 26-mm square and a length of $130 \mathrm{~mm}$ were machined to match the ECAP inlet channel. Six passes of 2-turn ECAP were conducted at room temperature using a die with an S-shaped channel of two $110^{\circ}$ angles. The inlet outlet channels were offset by 1.5 units by connecting them with a middle-inclined channel where the unit equals the channel width. The pressing was performed using a commercial $100 \mathrm{kN}$ hydraulic press. The total true strain obtained in the ECAP process is $\sim 10.7$. The processing was conducted with a $90^{\circ}$ sample rotation (route $B_{C}$ ) between passes, which corresponds to a combined route. During the 2-turn ECAP in the S-shaped channel, because of the shearing reverse, the second turn of the billet is equivalent to a $180^{\circ}$ rotation between two passes of conventional ECAP [20], which is known as route $C$. After each single pass through the 2-turn ECAP die, the sample was $90^{\circ}$ rotated about its axis, and so, the exact applied route of six passes is a sixfold C + Bc.

The samples in both the initial and deformed states were examined in terms of their microstructural changes, mechanical properties, corrosion resistance, electrical conductivity and thermal stability, since

Table 1 Chemical composition of examined ETP copper (wt\%)

\begin{tabular}{llll}
\hline $\mathrm{Cu}$ & $\mathrm{Bi}$ & $\mathrm{O}$ & $\mathrm{Pb}$ \\
\hline $\min 99.9$ & $\max 0.0005$ & $\max 0.04$ & $\max 0.005$ \\
\hline
\end{tabular}

these are properties essential for industrial applications.

The microstructure was examined by electron backscatter diffraction (EBSD) analysis using a Hitachi SU-70 scanning electron microscope (SEM) with an accelerating voltage of $20 \mathrm{kV}$. Apart from orientation imaging maps (OIM), misorientation angle distribution and quantitative data regarding grains sizes and shapes were obtained from the EBSD measurements. The analyses were performed on an area containing more than 1 million points (pixels). Representative regions were chosen for presentation. In the case of the sample in the initial state, a $0.5 \mu \mathrm{m}$ step was chosen, while for the deformed sample - $50 \mathrm{~nm}$. The samples for the EBSD testing were prepared by grinding and then electropolishing on a Tenupol-5 system with a voltage of $9 \mathrm{kV}$ and a temperature of $20{ }^{\circ} \mathrm{C}$. The detailed microstructure observations of the deformed copper were made using a JEOL JEM 1200 transmission electron microscope (TEM) with an accelerating voltage of $120 \mathrm{kV}$. The samples were prepared in the same way as for the EBSD analysis. The microstructure characterization was conducted on the $X$ (transverse), $Y$ (flow) and $Z$ (normal) planes [10] for the deformed sample (EBSD, TEM) and on the planes transverse and parallel to the extrusion (i.e., longitudinal) direction for the initial sample (EBSD).

The mechanical properties were investigated using tensile tests, which were performed on samples cut in the direction parallel to the flow direction in the ECAP and parallel to the extrusion direction for the initial sample. Flat mini-samples were used, as presented in Fig. 1. The thickness of the samples was $1.2 \mathrm{~mm}$. The tensile tests were conducted using a Zwick/Roell testing machine with optical non-contact displacement measurements using digital image correlation (DIC) for accurate strain determination. The tests were conducted at a strain rate of $10^{-3} \mathrm{~s}^{-1}$ at room temperature. Four tensile samples were tested for the copper in both its initial and deformed states. After the tensile tests, the fracture surfaces were observed using SEM.

Corrosion behavior was examined in a solution containing $3.5 \mathrm{wt} \% \mathrm{NaCl}$, as copper is sensitive to localized corrosion in an aggressive chloride environment. Measurements were performed on the samples after grinding and polishing up to $1 \mu \mathrm{m}$ diamond paste. Open-circuit potential (OCP) and 


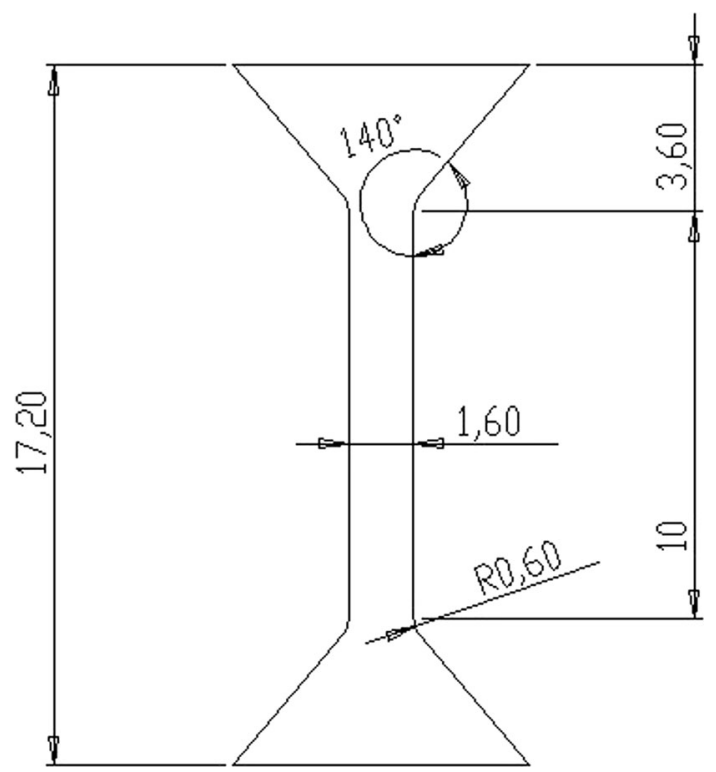

Figure 1 Schematic illustration of tensile specimen.

potentiodynamic polarization (PP) were performed. Electrochemical measurements were conducted using an AutoLab PGSTAT32 N potentiostat/galvanostat. A conventional three-electrode cell was used, with a Pt wire as the counter electrode and a silver chloride electrode as the reference electrode. The OCP was observed over $30 \mathrm{~min}$ of immersion in the test solution. Potentiodynamic polarization scans were initiated after $30 \mathrm{~min}$ of immersion, with a scan rate of $1 \mathrm{mV} / \mathrm{s}$.

Electrical conductivity was measured at room temperature using the eddy current method on a SIMGASCOPE SMP10 device according to DIN EN 2004-1 and ASTM E 1004 standards. Prior to the measurements, the surface of each specimen was mechanically polished in order to remove any artifacts. The electrical conductivity was expressed as a relative value of the International Annealed Copper Standard (\%IACS).

The thermal stability of the deformed sample was estimated by the micro-hardness measurements of samples after annealing at temperatures of 50, 75, $100,125,150,175$ and $200{ }^{\circ} \mathrm{C}$, for $15,30,45$ and $60 \mathrm{~min}$. For comparison purposes, the micro-hardness of the initial sample was measured at the boundary conditions. The micro-hardness measurements were performed using the Vicker's method with a load of $200 \mathrm{~g}$ (Hv0.2).

\section{Results and discussion}

\section{Microstructure}

The OIMs for the initial state are presented in Fig. 2, which shows those planes transverse and parallel to the extrusion direction. Quantitative data on the microstructure are presented in Table 2. The average grain size, including twins, is about $15.3 \mu \mathrm{m}$ for the transverse plane and $15.9 \mu \mathrm{m}$ for the plane parallel to the extrusion direction. The $\mathrm{CV}$ factor (the ratio of standard deviation to average grain size) for both planes shows a high value-above 1 , which indicates that the structure has a considerable variety of grain sizes. The elongation factor $\alpha$ (the ratio of maximum diameter to average diameter) is higher for the parallel plane and equals 1.84, indicating elongated grains in comparison with grains having an equiaxial shape (ideal circle) $\alpha=1$. The sample in the initial state exhibits a very high percentage of high-angle grain boundaries (HAGBs), above $80 \%$ (see Table 2). The histograms of misorientation angle distributions (Fig. 4) are similar for both planes, with the highest peak corresponding to the twin boundaries, indicating the recrystallized microstructure.

The OIMs for the deformed sample for the three characteristic ECAP planes $X, Y$ and $Z$ are shown in Fig. 3. A distinct grain size reduction is observed in the OIMs, with the quantitative data summarized in Table 2. The average grain size is significantly reduced, from above $15 \mu \mathrm{m}$ to 550-680 $\mathrm{nm}$. Differences between the $X$ and $Z$ planes are negligible and are about $30 \mathrm{~nm}$. The $Y$ plane exhibits the highest average grain size, about $680 \mathrm{~nm}$. Nevertheless, this plane is characterized by the most homogenous grains in terms of their size distribution, with a CV of 0.65. The elongation factor $\alpha$ is comparable for all planes, at about 1.4 , which indicates a near equiaxial microstructure. The amount of HAGBs is almost $60 \%$ and is similar for all planes, with a slight increase for the $Y$ plane. The histograms of misorientation angle distribution (Fig. 4) are very similar and typical for SPD-processed materials, where the highest peaks are for low misorientation angles.

It is commonly accepted that the optimal deformation route in ECAP for the formation of an ultrafine-grained equiaxial structure is route $B_{C}$ with a rotation by $90^{\circ}$ around the $X$-axis between consecutive passes [32]. On the other hand, the route A was revealed as the route having the highest efficiency in 

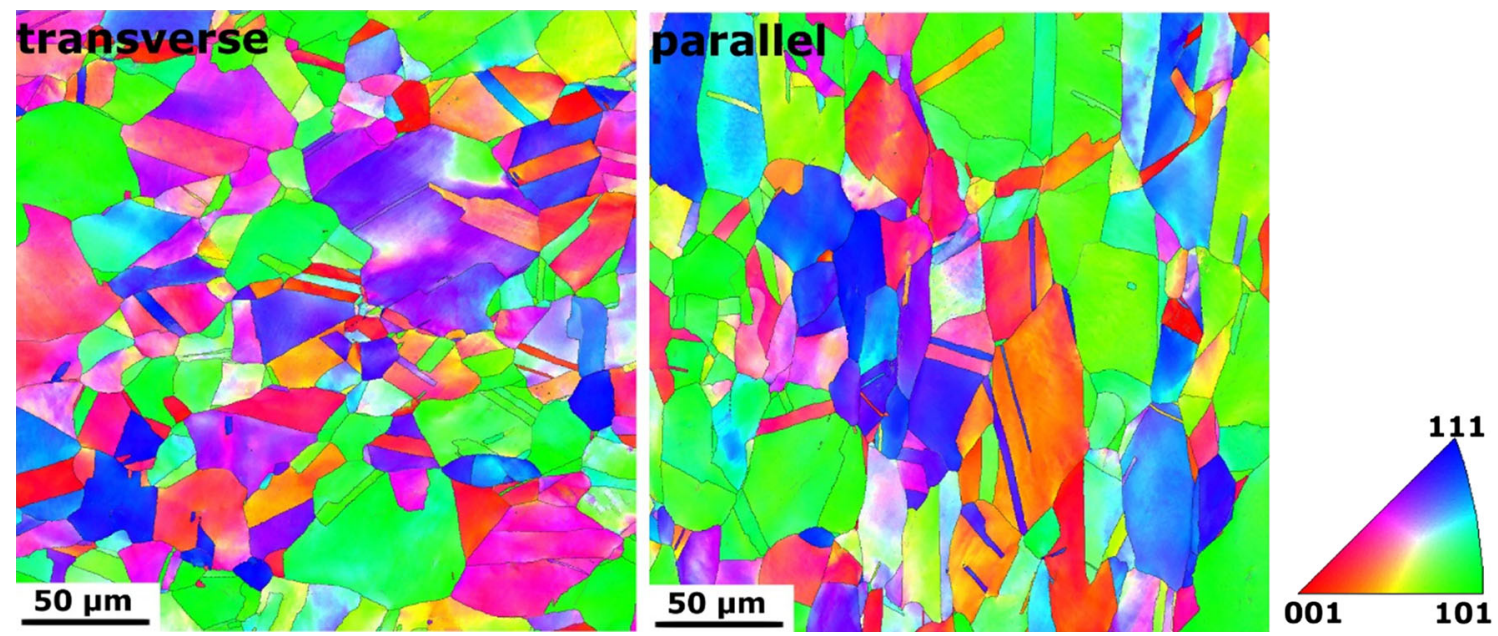

Figure 2 Orientation maps of the initial $\mathrm{Cu}$ sample: planes transverse and parallel to extrusion direction.

Table 2 Quantitative data describing microstructural features of $\mathrm{Cu}$ in the initial and deformed states

\begin{tabular}{lrrrl}
\hline & $d(\mathrm{~nm})$ & $\mathrm{CV}$ & $\alpha$ & HAGBs $(\%)$ \\
\hline Initial transverse & 15342 & 1.11 & 1.76 & 85.2 \\
Initial parallel & 15886 & 1.21 & 1.83 & 80.3 \\
ECAP-PC X & 553 & 0.86 & 1.38 & 55.6 \\
ECAP-PC $Y$ & 681 & 0.65 & 1.41 & 59.2 \\
ECAP-PC $Z$ & 580 & 0.82 & 1.39 & 58.6 \\
\hline
\end{tabular}

terms of high-angle grain boundary formation, due to a lack of redundant strain [33]. The route $C$, in turn, yields a uniform effective strain distribution [34], which can lead to a more homogenous microstructure and hence more isotropic properties. In the present study, a combination of routes $C$ and $B_{C}$ was applied, which should combine the advantages of the two. The microstructure of the ETP copper after
mtECAP was very uniform in the three planes investigated, meaning that the grains were close to equiaxial and similar in size. Nevertheless, the final grain size was larger than for the ECAP route $B_{C}[35]$, which yields an average grain size of below $500 \mathrm{~nm}$ for the applied strain of 13.2. Also, in the ECAP process with 16 passes using the route $B_{C}$, the grain size was estimated to be $0.49 \mu \mathrm{m}$ [26].

To be considered as UFG, a structure needs to consist mainly of high-angle grain boundaries (usually at a level of 70\%) [36]. For pure copper, such a value is extremely difficult to achieve. In the present study, the fraction of HAGBs is close to $60 \%$, which is superior compared to other reports. In [35], the fraction of HAGBS was estimated as $50 \%$ after deformation using an ECAP process with 12 passes of the route $B_{C}$ (a total equivalent strain of 13.8), while after 10 passes of ECAP of pure copper, the amount of HAGBs was $36-46 \%$ and did not depend on which
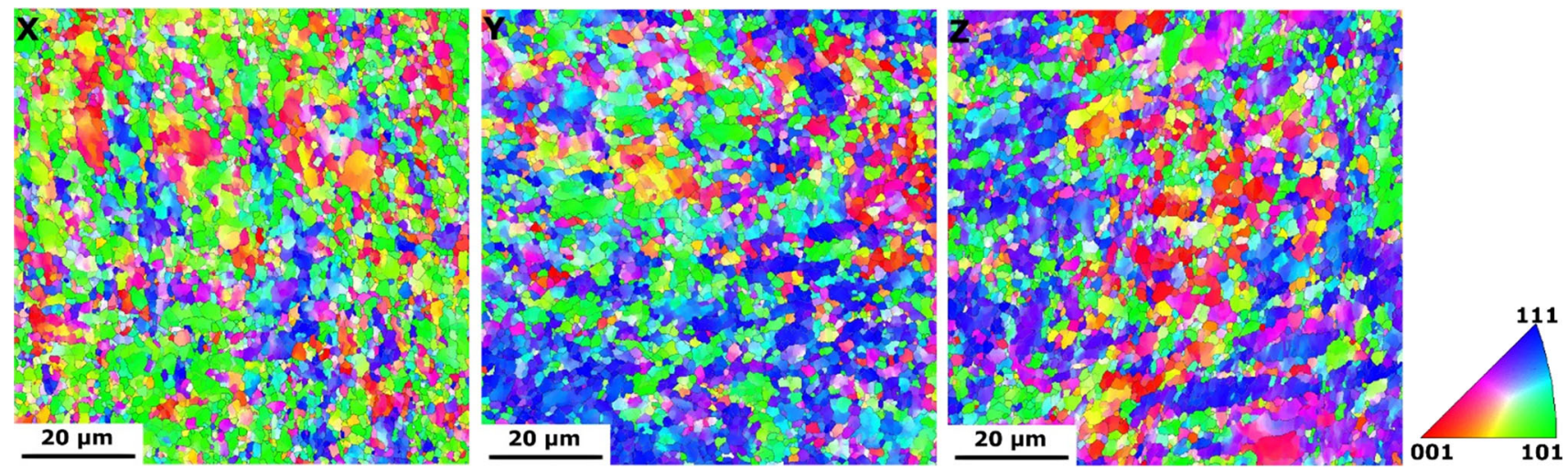

Figure 3 Orientation maps of the deformed $\mathrm{Cu}$ sample; $X, Y, Z$ planes according to ECAP markings. 

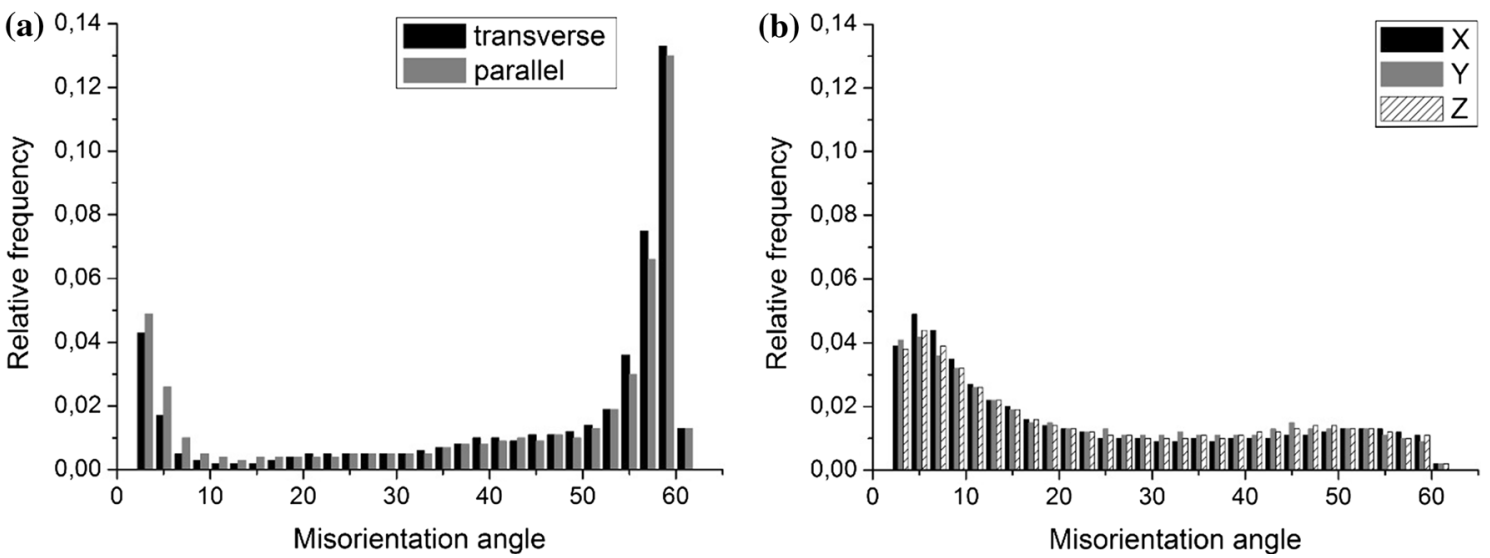

Figure 4 Misorientation angle distribution histograms for a the initial state (transverse and parallel planes) and $\mathbf{b}$ after deformation $(X$, $Y$ and $Z$ planes).

plane was examined [37]. Therefore, one can conclude that, despite the higher value of the average grain size, the mtECAP process together with the chosen deformation route led to a microstructure of ETP copper with a higher content of HAGBs than in the conventional ECAP process.

The process of grain refinement in copper begins with the formation of dislocation cells in the primary grains. With successive mtECAP passes and increased applied strain, the misorientation angles between the grains increase, eventually reaching a high-angle regime. However, even after the high total strain in the present study ( $\sim 10.7)$, the microstructure consists of a relatively high density of dislocation boundaries (40\%) which have not been transformed into HAGBs. Figure 5 shows TEM images of the microstructures for the $X, Y$ and $Z$ planes for deformed copper. There is still a relatively high density of dislocations and cells inside the grains, which was also reported for copper in other works [38, 39], even at higher strains [35]. In [37], after 10 passes of ECAP the microstructure consisted of both equiaxial and elongated grains with a majority of LAGBs. Only after subsequent rolling did the microstructure become more equiaxial. In the case of the present study, slightly elongated grains are still visible after deformation. The lamellar structure with LAGBs in their interiors can be mostly seen in the $Y$ plane (Fig. 3). The $X$ and $Z$ planes feature more equiaxial grains. It should be noted that, for deformation using routes $\mathrm{A}$ and $\mathrm{C}$, highly elongated grains were obtained [40].

Differences between particular planes are commonly observed in samples after ECAP [41]. By changing the shearing characteristics, different shapes and sizes of grains can be produced. Such changes can be implemented by rotating the sample between consecutive passes. Changes in slip systems occur, and these cause differences between the three orthogonal planes- $X, Y$ and $Z$. It has been proved experimentally that, by applying different deformation routes $\left(\mathrm{A}, \mathrm{B}_{\mathrm{A}}, \mathrm{B}_{\mathrm{C}}, \mathrm{C}\right)$, grains having different characteristic result. Grain shape reflects the strain path implemented by the specific processing route [42]. In the present study, the microstructure of the deformed sample is a combination of route C (a shearing reverse in the second turn of the single pass) and $\mathrm{B}_{\mathrm{C}}$ (a $90^{\circ}$ rotation of the sample between passes). Each processing route results in different distortions in the cubic elements in the $X, Y$ and $Z$ planes [10]. The restoration of the elements in route $C$ is after each 2 passes, for route $B_{C}$-after each 4 passes. Route $B_{C}$ because of the wide range of angular shearing in all planes (and highest for the $X$ plane) is the most effective for forming equiaxial grains [41]. Furthermore, the microstructure is homogenous, while for the other routes an elongated grain shape results [15]. As a combination of routes was implemented in this study, an analysis of the differences between planes poses difficulties. TEM observations of a small region of the sample (Fig. 5) revealed the presence of elongated grains in the $Y$ plane only, which is the effect of the shearing reverse in the second turn of each pass. In the $Y$ plane using route $C$, shearing is performed only on those planes lying at $45^{\circ}$ to the $X$-axis. Therefore, the width of the subgrains does not change after further passes [41]. Nevertheless, rotation between passes (route $B_{C}$ ) caused a reduction in the 

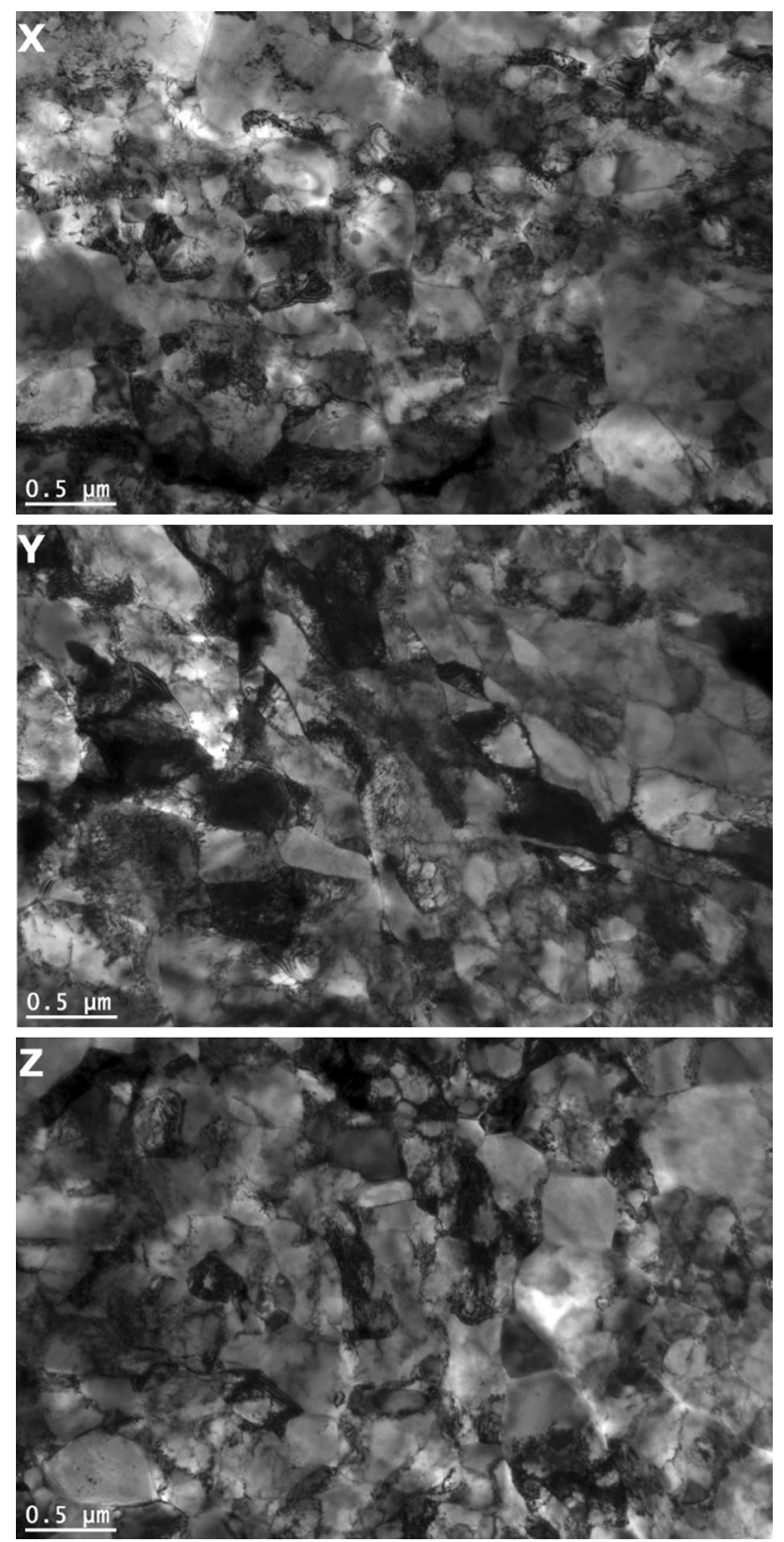

Figure 5 TEM figures of deformed copper; $X, Y, Z$ planes according to ECAP markings.

elongation of grains in the $Y$ plane. Route $B_{C}$ introduced several intersecting slip systems, which caused an increase in the density of dislocations. Dislocations after re-arrangement and annihilation create arrays of equiaxial grains in all three planes. Therefore, as can be seen from the present study and from stereological analysis of the EBSD measurements (Table 2), the differences in grain shape in particular planes, when a higher area is considered, are negligible.

\section{Mechanical properties}

The average data of yield strength (YS), ultimate tensile strength (UTS), elongation to break $(A)$ and uniform elongation $\left(A_{\mathrm{U}}\right)$ are listed in Table 3 . The YS and UTS values increased by about $50 \%$, while uniform elongation and elongation to failure decreased from 6.8 and $25 \%$ to 1.1 and $13.3 \%$, respectively. The distinct differences in mechanical strength were caused by the grain boundaries and dislocation strengthening mechanisms. The values of strength obtained are lower than those for pure copper after 12 passes of ECAP with or without backpressure, where the UTS was about $440 \mathrm{MPa}$ [43]. As was presented, the applied backpressure did not enhance strength, but did significantly improve elongation to break to above $20 \%$, but with $60 \%$ for the initial state. Nevertheless, similar results were achieved from the tensile tests in [37], where the UTS was about $400 \mathrm{MPa}$ and total elongation was below 13\% after ten passes of ECAP. Similar values of UTS and YS were also achieved for pure copper after four passes of ARB [24], while the average grain size, estimated from TEM observations, was about $200 \mathrm{~nm}$, which is significantly lower than in the present study.

The reduced value of uniform elongation for the deformed sample indicates rapid necking. This phenomenon has been observed for UFG copper [44] and also for other severely deformed metals, such as aluminum [45]. The flow stress quickly reaches a maximum value and then decreases gradually, and so, the total elongation is reduced as well. In the case of elongation, the ratio between LAGBs and HAGBs may play an important role. As was presented for aluminum alloys, it is possible to enhance ductility while retaining high strength by lowering the grain boundary misorientation angle [46]. This phenomenon is most pronounced when the lamellar structure is present in the microstructure. Dislocations are able to glide across the LAGBs and

Table 3 Values of ultimate tensile strength (UTS), yield strength (YS), elongation to break $(A)$ and uniform elongation $\left(A_{\mathrm{U}}\right)$ of the initial sample and after deformation

\begin{tabular}{lllll}
\hline & YS (MPa) & UTS (MPa) & $A_{\mathrm{U}}(\%)$ & $A(\%)$ \\
\hline Initial state & 245 & 251 & 6.8 & 25.1 \\
Deformed state & 374 & 393 & 1.1 & 13.3 \\
\hline
\end{tabular}


accumulate within the lamellar bands. In the present study, the lamellar structure (Fig. 5) with a fraction of LAGBs of $40 \%$ made it possible to achieve satisfactory plasticity of above $13 \%$.

Figure 6 shows fractures for both samples. The fractures are transcrystalline and ductile, with numerous dimples. A dimple-dominant fracture implies a more ductile fracture, as was shown for ECAP and ECAP with subsequent cold rolling [38]. The mechanism of formation of dimples consists of initiation, growth and coalescence of cavities. The dimples for the CG sample are of comparable size. After SPD processing, dimples with a greater diversity in terms of size can be observed. There are a few large dimples with smaller ones in their interiors. The large ones are formed as a result of the de-cohesive mechanism and the small ones by the dislocation mechanism [26]. Consequently, the higher dislocation density, which behaves as a nucleus of cavity initiation, the higher number of dimples. Their size is also connected with the dislocations. As was shown in [26], with an increasing number of ECAP passes, the number of small dimples increases, while their size decreases. Such differences can be also seen in the present study. The UFG sample, which is characterized as well by a high density of dislocations and dislocation cells (Fig. 5), displays a higher number of small dimples, which are hardly seen in the CG sample.

The strength of a material increases with decreasing average grain size, as described by the Hall-Petch equation [47, 48]. Figure 7 presents a Hall-Petch plot (YS as a function of the inverse square root of average grain size) for CG and UFG ETP copper, using the results obtained in the present study and data from the literature. Generally, the experimental data follow

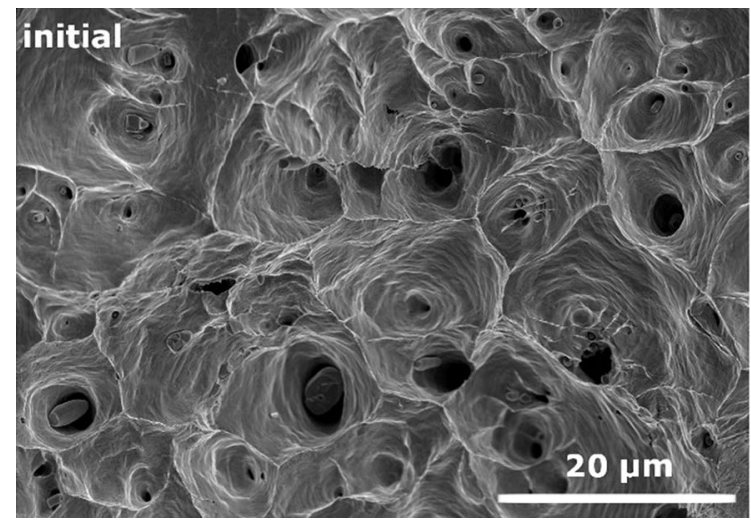

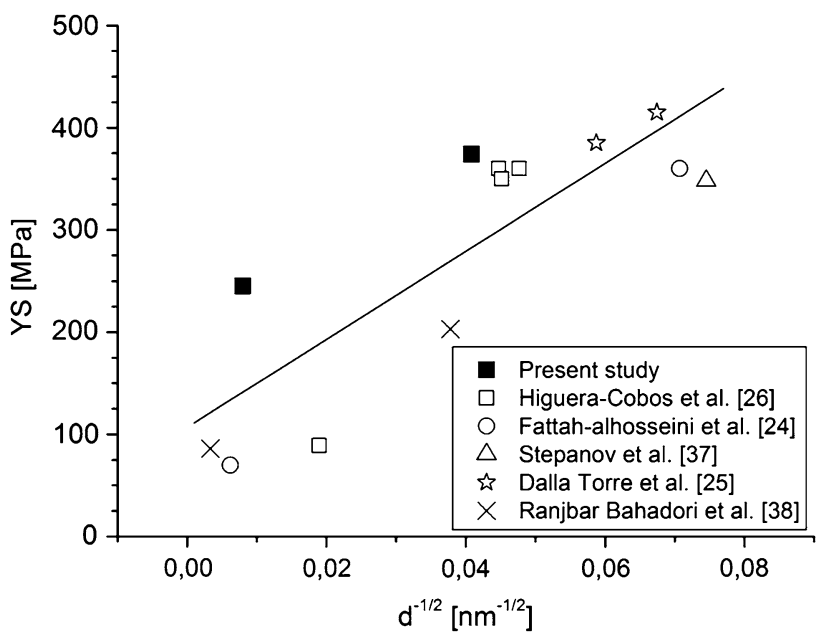

Figure 7 Relationship between average grain size and YS for pure copper samples from the present study and literature data.

a certain trend (marked with a black continuous line), although there is a considerable scattering of data points around the trend line. There are several factors influencing the deviation from the Hall-Petch relationship. First, the Hall-Petch analysis only considers average grain size, while real grain structures exhibit various grain size distributions, which have been shown to affect the strength of metals [49]. Also, the populations of grain boundaries may differ significantly, which strongly affects the strength of metals [50, 51]. In particular, slip transfer through LAGBs is much easier than through HAGBs, and therefore, these represent weaker barriers against the movement of lattice dislocations, resulting in a lower strengthening effect. It should also be noted that the position of points on the Hall-Petch plot may be affected by such factors as dislocation density and/or the content of impurities or alloying elements, as

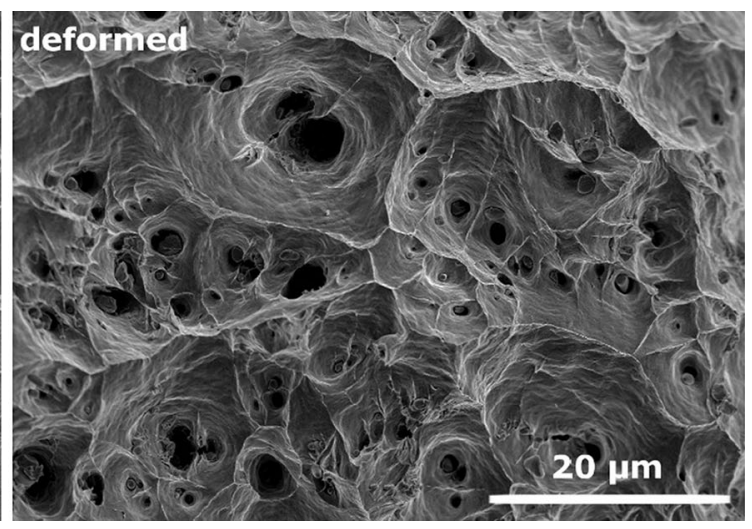

Figure 6 Fractures of initial (CG) and deformed (UFG) samples. 
these also contribute to the strength of a material. The microstructure of pure copper processed by various SPD methods [24-26, 37, 38], whose data are presented in Fig. 7, was described in terms of average grain size and may differ in other microstructural features mentioned above. The results obtained in the present study, which are marked as black full squares in Fig. 7, are located above the trend line for both the initial and the deformed samples, which can be attributed to a lower purity of the examined ETP copper $(99.9 \%)$ resulting in higher yield strength.

\section{Corrosion behavior}

Open-circuit potential (OCP) and potentiodynamic polarization (PP) curves are shown in Fig. 8. The OCP curves are similar, while for the deformed sample stabilization was achieved faster. After $30 \mathrm{~min}$ of immersion, the OCP potential shows exactly the same value for both samples. The PP curves also reveal the same character, but there are some differences between the examined samples. The corrosion potential is lower for the initial sample. The differences are not significant, as for the CG sample $E_{\text {corr }}$ equals0.28 $\mathrm{V}_{\mathrm{Ag} / \mathrm{AgCl}}$, while for the UFG sample it is - $0.26 \mathrm{~V}_{\mathrm{Ag} / \mathrm{AgCl}}$. However, the corrosion current density is lower for the non-deformed sample and equals $1.1 \mu \mathrm{A} / \mathrm{cm}^{2}$, with $4.2 \mu \mathrm{A} / \mathrm{cm}^{2}$ for the UFG copper. A region of passivation can be observed in both samples. The observed pitting potential is higher for the UFG sample than for the CG sample, at $-0.05 \mathrm{~V}_{\mathrm{Ag} / \mathrm{AgCl}}$ and $-0.13 \mathrm{~V}_{\mathrm{Ag} / \mathrm{AgCl}}$, respectively. The results obtained from the electrochemical measurements in $3.5 \% \mathrm{NaCl}$ show that the deformation process caused a slight improvement in corrosion resistance, as the corrosion potential is nobler for the UFG copper. Moreover, the UFG sample displays a lower susceptibility to localized corrosion. Nevertheless, the higher corrosion current density for the deformed ETP copper results in a higher corrosion rate [52].

The dependence between corrosion resistance and grain size has been studied widely. Nonetheless, the results obtained differ significantly, and there is no direct answer to the relationship between these two parameters. For pure aluminum after rotary swaging, the grain refinement caused an enhancement in corrosion resistance [53]. This has been explained by the easier formation of passive films due to the elevated number of defects such as grain boundaries and dislocations, where oxidation of the metal occurs. Moreover, the passive film in the UFG material was more stable and integral due to internal stresses. The corrosion behavior - the shape of polarization curves and the corrosion attack type-does not vary between the UFG and the CG copper. Although in [29] UFG copper was found to be a material with a higher average dissolution rate, caused by the elevated amount of grain boundaries, it revealed much lower localization of corrosion. Similar results were obtained in [30], where the corrosion damage in UFG copper was much more uniformly distributed in comparison with the CG sample, where selective corrosion was observed. In [52], the authors proposed a model where, in the traditional Hall-Petch relationship, the yield behavior of the material was (a)

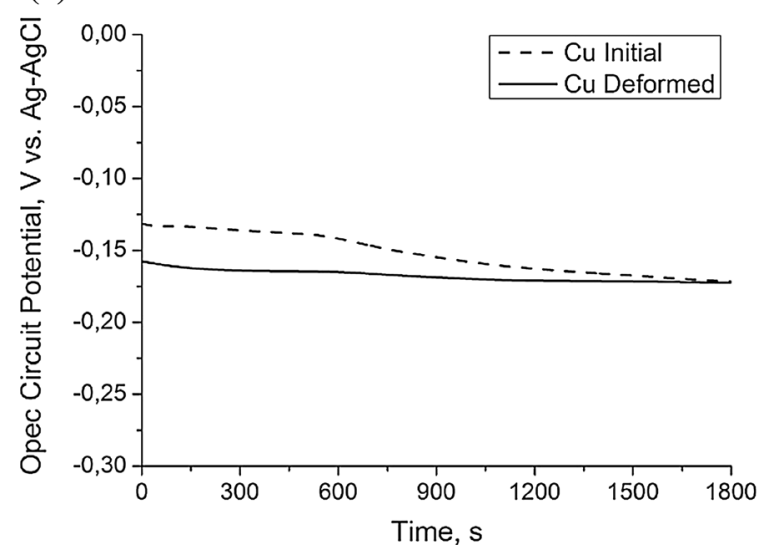

(b)

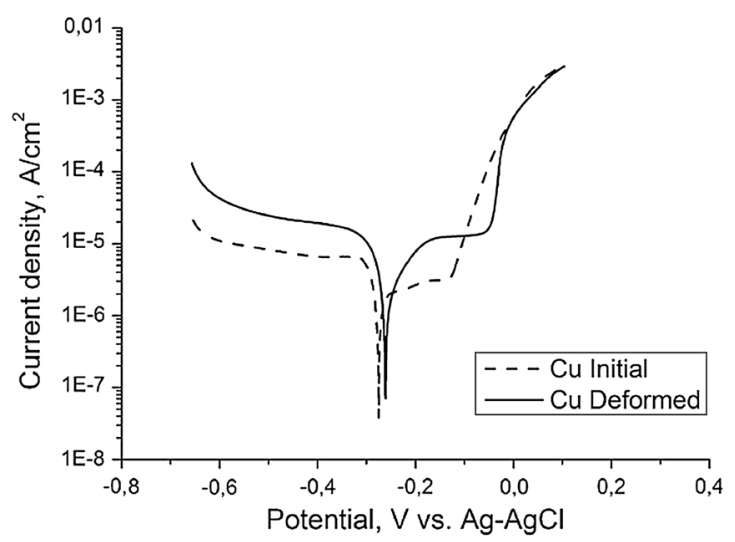

Figure 8 Electrochemical testing for ETP copper samples: a open-circuit potential changes during 30-min immersion and b potentiodynamic polarization curves recorded in $3.5 \% \mathrm{NaCl}$ at room temperature. 
replaced with the corrosion rate. As was shown, the corrosion rate depends on passivity, but when passivity or an oxide exists, the grain refinement causes a reduction in the corrosion rate. However, in the absence of an oxide film, the increased number of grain boundaries enhances overall surface reactivity, causing the corrosion rate to increase as well. From the present experiment, the conclusion can be drawn that a refinement in the microstructure of pure copper increases its corrosion resistance in the environment investigated. However, further studies are needed to fully understand the corrosion behavior of UFG copper, particularly surface damage and the dissolution rate.

\section{Electrical conductivity}

The ETP copper in the initial state exhibits an electrical conductivity of $100.2 \%$ IACS. Grain refinement by mtECAP caused a reduction to $93.1 \%$ IACS. This phenomenon has been observed before $[1,6,26]$ and is explained by the electron scattering caused by the structural defects. As was shown, the lattice stresses are the highest for foreign atoms [6, 31], and so, alloying elements in a solid solution are the most detrimental for electrical conductivity. SPD processing and the resulting grain refinement bring about a decrease in the electrical conductivity of pure metals and non-heat-treatable alloys, as reported for commercially pure aluminum and $\mathrm{Al}-\mathrm{Mg}-\mathrm{Mn}$ alloy [6]. However, the electrical conductivity of SPD-processed alloys can be enhanced if an aging process is employed after deformation [31, 54, 55].

It should be noted that the decrease in electrical conductivity caused by grain refinement in copper is not significant. The literature data show that a grain size reduction to $200 \mathrm{~nm}$ did not cause any significant change, as the electrical conductivity decreased by only about $4 \%$ IACS [1]. Even less distinct differences were observed in [26], where the change between undeformed pure copper and copper after 16 passes of ECAP was $\sim 2 \%$ IACS. In the present study, that difference is slightly higher-about 7\% IACS, although the copper used was of a lower purity. With lower purity or a higher content of alloying elements, the differences between the CG and the UFG copper will be more pronounced, as in the case of $\mathrm{Cu}-3 \mathrm{wt} \%$ $\mathrm{Ag}$, where after eight passes of ECAP the electrical conductivity decreased from $97 \%$ IACS to $87 \%$ IACS [2].

\section{Thermal stability}

The thermal stability of the mtECAP-processed sample was determined by annealing samples at seven temperatures, from $50{ }^{\circ} \mathrm{C}$ do $200{ }^{\circ} \mathrm{C}$, in steps of $25^{\circ} \mathrm{C}$. The micro-hardness was measured after 15,30 , 45 and $60 \mathrm{~min}$ of annealing. The results are presented in Fig. 9. As can be seen, for annealing at $50{ }^{\circ} \mathrm{C}$, the micro-hardness is constant over the periods of time investigated and is estimated at 127-129 Hv0.2. For annealing at $75{ }^{\circ} \mathrm{C}$, the micro-hardness decreases slightly only after $1 \mathrm{~h}$. For the temperatures 100-150 ${ }^{\circ}$ $C$, there is a slight drop in micro-hardness at the beginning of the annealing, and it remains constant for longer times. Furthermore, for all three temperatures this drop is the same, and the micro-hardness is about $120 \mathrm{Hv} 0.2$. Only annealing at higher temperatures causes distinct differences in the micro-hardness of the deformed ETP copper. A temperature of $175{ }^{\circ} \mathrm{C}$ causes a decrease from $115 \mathrm{Hv} 0.2$ to $105 \mathrm{Hv} 0.2$, depending on the annealing time. A temperature of $200{ }^{\circ} \mathrm{C}$ causes even more pronounced changes, with the micro-hardness decreasing to about $83 \mathrm{Hv} 0.2$. What is more, the values at 45 and $60 \mathrm{~min}$ are comparable, which may be evidence of structure stability at this temperature. For the undeformed sample, the initial value of micro-hardness was about $105 \mathrm{Hv} 0.2$, and this also decreased after annealing at $200{ }^{\circ} \mathrm{C}$ for $60 \mathrm{~min}$ to $85 \mathrm{Hv} 0.2$, which is similar to the value for the deformed copper annealed under the same conditions.

The thermal stability of the samples after SPD processing was relatively low, due to a high stored

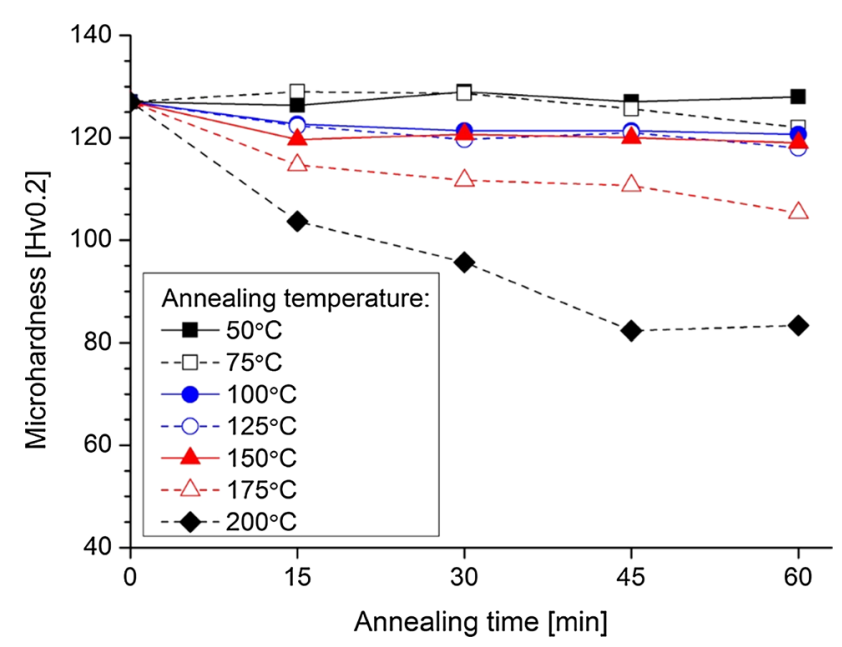

Figure 9 Thermal stability of deformed sample of $\mathrm{Cu}$. 
energy and a low apparent activation energy for recrystallization [56]. The recrystallization temperature of the deformed materials decreased sharply with increasing strain, but after a steady grain size in the UFG copper, the recrystallization temperature become independent of the stored energy [57]. As was shown in the case of UFG copper, the microstructure coarsening occurs through discontinuous recrystallization and is caused by heterogeneities induced by the SPD processing and improved nucleation conditions [35]. The results presented are promising for potential applications. The thermal stability of mtECAP-processed copper is enhanced in comparison with other studies, where annealing for $10 \mathrm{~min}$ at $150{ }^{\circ} \mathrm{C}$ caused a steep drop in micro-hardness, meaning in the recrystallization process [43]. The relatively small drop in microhardness in the present study up to a temperature of $150{ }^{\circ} \mathrm{C}$ is caused by a recovery process. Generally, the thermal stability of UFG copper is assumed up to a temperature of $120-150{ }^{\circ} \mathrm{C}$, while above $150{ }^{\circ} \mathrm{C}$ recovery followed by recrystallization and abnormal grain growth is observed [58].

\section{Conclusions}

From the experiments conducted, the following conclusions can be drawn:

1. The mtECAP process revealed a high efficiency in terms of grain refinement in ETP copper (a grain size reduction from almost $16 \mu \mathrm{m}$ to about $600 \mathrm{~nm}$ after six passes was obtained). In addition, mtECAP led to a UFG microstructure with the fraction of HAGBs of about $60 \%$, regardless of the plane examined.

2. The grain refinement caused an improvement in YS and UTS of about $50 \%$, with a decrease in elongation to failure to a satisfactory value of $13.3 \%$.

3. The UFG sample revealed higher corrosion and pitting potentials, which indicates better corrosion resistance in a $3.5 \% \mathrm{NaCl}$ environment. Meanwhile, a higher corrosion current density was obtained for the UFG sample, which may result in a higher corrosion rate.

4. The grain refinement caused only a slight decrease in electrical conductivity (7\% IACS).
5. mtECAP-processed ETP copper is thermally stable up to a temperature of $150{ }^{\circ} \mathrm{C}$ for $1 \mathrm{~h}$ of annealing. At higher temperatures, a significant drop in micro-hardness is observed, which is related to the recrystallization process.

6. The enhancement in mechanical strength while maintaining high electrical conductivity and thermal stability makes UFG copper processed by mtECAP attractive for industrial applications such as electrical installations.

Processing with the mtECAP method makes it possible to control the properties of a material by controlling its microstructure. There is enormous potential for optimizing mechanical strength and electrical conductivity, which are crucial for applications of electrolytic tough pitch copper. This material is broadly used in industry, but as was shown in the present study, its properties can be further enhanced. For this purpose, the mtECAP method is superior, as a process with unlimited potential for deforming materials and facilitating modifications of them.

\section{Acknowledgements}

This work was carried out within the statutory funds to the Faculty of Materials Science and Engineering of Warsaw University of Technology.

\section{Compliance with ethical standards}

Conflict of interest The authors state that no conflicts of interest exist.

Open Access This article is distributed under the terms of the Creative Commons Attribution 4.0 International License (http://creativecommons.org/ licenses/by/4.0/), which permits unrestricted use, distribution, and reproduction in any medium, provided you give appropriate credit to the original author(s) and the source, provide a link to the Creative Commons license, and indicate if changes were made.

\section{References}

[1] Takata N, Lee S-H, Tsuji N (2009) Ultrafine grained copper alloy sheets having both high strength and high electric 
conductivity. Mater Lett 63:1757-1760. https://doi.org/10. 1016/j.matlet.2009.05.021

[2] Ko YG, Namgung S, Lee BU, Shin DH (2010) Mechanical and electrical responses of nanostructured $\mathrm{Cu}-3 \mathrm{wt} \% \mathrm{Ag}$ alloy fabricated by ECAP and cold rolling. J Alloys Compd 504: S448-S451. https://doi.org/10.1016/j.jallcom.2010.02.198

[3] Hosseini SA, Manesh HD (2009) High-strength, high-conductivity ultra-fine grains commercial pure copper produced by ARB process. Mater Des 30:2911-2918. https://doi.org/ 10.1016/j.matdes.2009.01.012

[4] Wei KX, Wei W, Wang F, Du QB, Alexandrov IV, Hu J (2011) Microstructure, mechanical properties and electrical conductivity of industrial $\mathrm{Cu}-0.5 \% \mathrm{Cr}$ alloy processed by severe plastic deformation. Mater Sci Eng A 528:14781484. https://doi.org/10.1016/j.msea.2010.10.059

[5] Murashkin MY, Sabirov I, Medvedev AE, Enikeev NA, Lefebvre W, Valiev RZ et al (2016) Mechanical and electrical properties of an ultrafine grained Al-8.5wt. \% RE $(\mathrm{RE}=5.4 \mathrm{wt} . \% \mathrm{Ce}, 3.1 \mathrm{wt} . \% \mathrm{La})$ alloy processed by severe plastic deformation. Mater Des 90:433-442. https://doi.org/ 10.1016/j.matdes.2015.10.163

[6] Lipińska M, Bazarnik P, Lewandowska M (2016) The influence of severe plastic deformation processes on electrical conductivity of commercially pure aluminium and 5483 aluminium alloy. Arch Civ Mech Eng 16:717-723. https://doi.org/10.1016/j.acme.2016.04.013

[7] Meyers MA, Mishra A, Benson DJ (2006) Mechanical properties of nanocrystalline materials. Prog Mater Sci 51:427-556. https://doi.org/10.1016/j.pmatsci.2005.08.003

[8] Furukawa M, Horita Z, Nemoto M, Langdon TG (2002) The use of severe plastic deformation for microstructural control. Mater Sci Eng A 324:82-89. https://doi.org/10.1016/S09215093(01)01288-6

[9] Valiev RZ, Langdon TG (2006) Principles of equal-channel angular pressing as a processing tool for grain refinement. Prog Mater Sci 51:881-981. https://doi.org/10.1016/j. pmatsci.2006.02.003

[10] Furukawa M, Iwahashi Y, Horita Z, Nemoto M, Langdon TG (1998) The shearing characteristics associated with equalchannel angular pressing. Mater Sci Eng A 257:328-332. https://doi.org/10.1016/S0921-5093(98)00750-3

[11] Segal VM (1995) Materials processing by simple shear. Mater Sci Eng A 197:157-164. https://doi.org/10.1016/ 0921-5093(95)09705-8

[12] Nakashima K, Horita Z, Nemoto M, Langdon TG (2000) Development of a multi-pass facility for equal-channel angular processing to high total strains. Mater Sci Eng A 281:82-87. https://doi.org/10.1016/S0921-5093(99)00744-3

[13] Akira M, Yoshiyuki O, Masakazu O (2003) Die for extrusion, and apparatus and method for manufacturing finestructured metallic material (Mitsubishi Heavy Ind. Ltd.). Japan Patent 245712

[14] Rosochowski M, Olejnik A, Richert L (2007) 3D-ECAP of square aluminium billets. In: Banabic D (ed) Advanced methods material form. Springer, Paris, pp 215-232

[15] Langdon TG, Furukawa M, Nemoto M, Horita Z (2000) Using equal-channel angular pressing for refining grain size. JOM 52:30-33. https://doi.org/10.1007/s11837-000-0128-7

[16] Raab GI (2005) Plastic flow at equal channel angular processing in parallel channels. Mater Sci Eng A 410-411:230233. https://doi.org/10.1016/j.msea.2005.08.089

[17] Olejnik L, Rosochowski A (2008) Scaled-up ECAP with enhanced productivity. Steel Res Int Spec Ed 2:439-446

[18] Rosochowski A (ed) (2017) Severe plastic deformation technology. Whittles Publishing, Dunbeath

[19] Djavanroodi F, Ebrahimi M (2010) Effect of die parameters and material properties in ECAP with parallel channels. Mater Sci Eng A 527:7593-7599. https://doi.org/10.1016/j. msea.2010.08.022

[20] Rosochowski A, Olejnik L (2002) Numerical and physical modelling of plastic deformation in 2-turn equal channel angular extrusion. J Mater Process Technol 125-126:309316. https://doi.org/10.1016/S0924-0136(02)00339-4

[21] Hebesberger T, Stüwe HP, Vorhauer A, Wetscher F, Pippan R (2005) Structure of $\mathrm{Cu}$ deformed by high pressure torsion. Acta Mater 53:393-402. https://doi.org/10.1016/j.actamat.2004.09.043

[22] Horita Z, Langdon TG (2005) Microstructures and microhardness of an aluminum alloy and pure copper after processing by high-pressure torsion. Mater Sci Eng A 410 411:422-425. https://doi.org/10.1016/j.msea.2005.08.133

[23] Edalati K, Fujioka T, Horita Z (2008) Microstructure and mechanical properties of pure $\mathrm{Cu}$ processed by high-pressure torsion. Mater Sci Eng A 497:168-173. https://doi.org/10. 1016/j.msea.2008.06.039

[24] Fattah-alhosseini A, Imantalab O, Mazaheri Y, Keshavarz MK (2016) Microstructural evolution, mechanical properties, and strain hardening behavior of ultrafine grained commercial pure copper during the accumulative roll bonding process. Mater Sci Eng A 650:8-14. https://doi.org/ 10.1016/j.msea.2015.10.043

[25] Dalla Torre F, Lapovok R, Sandlin J, Thomson PF, Davies CHJ, Pereloma EV (2004) Microstructures and properties of copper processed by equal channel angular extrusion for 116 passes. Acta Mater 52:4819-4832. https://doi.org/10. 1016/j.actamat.2004.06.040

[26] Higuera-Cobos OF, Cabrera JM (2013) Mechanical, microstructural and electrical evolution of commercially pure copper processed by equal channel angular extrusion. Mater Sci Eng A 571:103-114. https://doi.org/10.1016/j. msea.2013.01.076 
[27] Lugo N, Llorca N, Cabrera JM, Horita Z (2008) Microstructures and mechanical properties of pure copper deformed severely by equal-channel angular pressing and high pressure torsion. Mater Sci Eng A 477:366-371. https:// doi.org/10.1016/j.msea.2007.05.083

[28] Mishra A, Richard V, Grégori F, Asaro RJ, Meyers MA (2005) Microstructural evolution in copper processed by severe plastic deformation. Mater Sci Eng A 410-411:290298. https://doi.org/10.1016/j.msea.2005.08.201

[29] Vinogradov A, Mimaki T, Hashimoto S, Valiev R (1999) On the corrosion behaviour of ultra-fine grain copper. Scr Mater 41:319-326. https://doi.org/10.1016/S1359-6462(99)00170-0

[30] Miyamoto H, Harada K, Mimaki T, Vinogradov A, Hashimoto S (2008) Corrosion of ultra-fine grained copper fabricated by equal-channel angular pressing. Corros Sci 50:1215-1220. https://doi.org/10.1016/j.corsci.2008.01.024

[31] Murashkin MY, Sabirov I, Sauvage X, Valiev RZ (2016) Nanostructured $\mathrm{Al}$ and $\mathrm{Cu}$ alloys with superior strength and electrical conductivity. J Mater Sci 51:33-49. https://doi.org/ 10.1007/s10853-015-9354-9

[32] Furukawa M, Horita Z, Langdon TG (2002) Factors influencing the shearing patterns in equal-channel angular pressing. Mater Sci Eng A 332:97-109. https://doi.org/10. 1016/S0921-5093(01)01716-6

[33] Gholinia A, Prangnell PB, Markushev MV (2000) Effect of strain path on the development of deformation structures in severely deformed aluminium alloys processed by ECAE. Acta Mater 48:1115-1130. https://doi.org/10.1016/S13596454(99)00388-2

[34] Xu S, Zhao G, Luan Y, Guan Y (2006) Numerical studies on processing routes and deformation mechanism of multi-pass equal channel angular pressing processes. J Mater Process Technol 176:251-259. https://doi.org/10.1016/j.jmatprotec. 2006.03.167

[35] Molodova X, Khorashadizadeh A, Gottstein G, Winning M, Hellmig RJ (2007) Thermal stability of ECAP processed pure $\mathrm{Cu}$ and $\mathrm{CuZr}$. Int J Mater Res 98:269-275. https://doi. org/10.1016/j.msea.2007.01.042

[36] Prangnell PB, Bowen JR, Apps PJ (2004) Ultra-fine grain structures in aluminium alloys by severe deformation processing. Mater Sci Eng A 375-377:178-185. https://doi.org/ 10.1016/j.msea.2003.10.170

[37] Stepanov ND, Kuznetsov AV, Salishchev GA, Raab GI, Valiev RZ (2012) Effect of cold rolling on microstructure and mechanical properties of copper subjected to ECAP with various numbers of passes. Mater Sci Eng A 554:105-115. https://doi.org/10.1016/j.msea.2012.06.022

[38] Ranjbar Bahadori S, Dehghani K, Bakhshandeh F (2013) Microstructure, texture and mechanical properties of pure copper processed by ECAP and subsequent cold rolling.
Mater Sci Eng A 583:36-42. https://doi.org/10.1016/j.msea. 2013.06.061

[39] Kim YG, Hwang B, Lee S, Lee CW, Shin DH (2009) Dynamic deformation and fracture behavior of ultra-finegrained pure copper fabricated by equal channel angular pressing. Mater Sci Eng A 504:163-168. https://doi.org/10. 1016/j.msea.2008.10.043

[40] Mishra A, Kad BK, Gregori F, Meyers MA (2007) Microstructural evolution in copper subjected to severe plastic deformation: experiments and analysis. Acta Mater 55:13-28. https://doi.org/10.1016/j.actamat.2006.07.008

[41] Langdon TG (2007) The principles of grain refinement in equal-channel angular pressing. Mater Sci Eng A 462:3-11. https://doi.org/10.1016/j.msea.2006.02.473

[42] Sun PL, Kao PW, Chang CP (2004) Effect of deformation route on microstructural development in aluminum processed by equal channel angular extrusion. Metall Mater Trans A 35:1359-1368. https://doi.org/10.1007/s11661-0040311-5

[43] Wang YL, Lapovok R, Wang JT, Qi YS, Estrin Y (2015) Thermal behavior of copper processed by ECAP with and without back pressure. Mater Sci Eng A 628:21-29. https:// doi.org/10.1016/j.msea.2015.01.021

[44] Salimyanfard F, Reza Toroghinejad M, Ashrafizadeh F, Jafari M (2011) EBSD analysis of nano-structured copper processed by ECAP. Mater Sci Eng A 528:5348-5355. https://doi.org/10.1016/j.msea.2011.03.075

[45] Kamachi M, Furukawa M, Horita Z, Langdon TG (2003) Equal-channel angular pressing using plate samples. Mater Sci Eng A 361:258-266. https://doi.org/10.1016/S09215093(03)00522-7

[46] Hu T, Ma K, Topping TD, Saller B, Yousefiani A, Schoenung JM et al (2014) Improving the tensile ductility and uniform elongation of high-strength ultrafine-grained $\mathrm{Al}$ alloys by lowering the grain boundary misorientation angle. Scr Mater 78-79:25-28. https://doi.org/10.1016/j.scriptamat. 2014.01 .020

[47] Hall EO (1951) The deformation and ageing of mild steel: III discussion of results. Proc Phys Soc Sect B 64:747. https:// doi.org/10.1088/0370-1301/64/9/303

[48] Petch NJ (1953) The cleavage strength of polycrystals. J Iron Steel Inst 174:25-28. https://doi.org/10.1007/BF01972547

[49] Dobosz R, Lewandowska M, Kurzydlowski KJ (2012) The effect of grain size diversity on the flow stress of nanocrystalline metals by finite-element modelling. Scr Mater 67:408-411. https://doi.org/10.1016/j.scriptamat. 2012.05.043

[50] Hansen N (2004) Hall-Petch relation and boundary strengthening. Scr Mater 51:801-806. https://doi.org/10. 1016/j.scriptamat.2004.06.002 
[51] Bazarnik P, Huang Y, Lewandowska M, Langdon TG (2015) Structural impact on the Hall-Petch relationship in an Al$5 \mathrm{Mg}$ alloy processed by high-pressure torsion. Mater Sci Eng A 626:9-15. https://doi.org/10.1016/j.msea.2014.12.027

[52] Ralston KD, Birbilis N, Davies CHJ (2010) Revealing the relationship between grain size and corrosion rate of metals. Scr Mater 63:1201-1204. https://doi.org/10.1016/j.scripta mat.2010.08.035

[53] Abdulstaar M, Mhaede M, Wagner L, Wollmann M (2014) Corrosion behaviour of Al 1050 severely deformed by rotary swaging. Mater Des 57(2014):325-329. https://doi.org/10. 1016/j.matdes.2014.01.005

[54] Valiev RZ, Murashkin M, Sabirov I (2014) A nanostructural design to produce high-strength $\mathrm{Al}$ alloys with enhanced electrical conductivity. Scr Mater 76:13-16. https://doi.org/ 10.1016/j.scriptamat.2013.12.002
[55] Lipinska M, Bazarnik P (2014) The electrical conductivity of $\mathrm{CuCrZr}$ alloy after SPD processing. IOP Conf Ser Mater Sci Eng. https://doi.org/10.1088/1757-899X/63/1/ 012119

[56] Cao WQ, Gu CF, Pereloma EV, Davies CHJ (2008) Stored energy, vacancies and thermal stability of ultra-fine grained copper. Mater Sci Eng A 492:74-79. https://doi.org/10.1016/ j.msea.2008.02.048

[57] Zhang Y, Wang JT, Cheng C, Liu J (2008) Stored energy and recrystallization temperature in high purity copper after equal channel angular pressing. J Mater Sci 43:7326-7330. https://doi.org/10.1007/s10853-008-2903-8

[58] Estrin Y, Vinogradov A (2013) Extreme grain refinement by severe plastic deformation: a wealth of challenging science. Acta Mater 61:782-817. https://doi.org/10.1016/j.actamat. 2012.10.038 